\title{
Müşteri İlişkileri Açısından Alışveriş Merkezlerinde Akılı Teknoloji Kullanımı
}

\section{Smart Technology Usage in Shopping Malls in Terms of Consumer Relations}

\author{
Arş. Gör. İbrahim Ethem ERDİNÇ \\ Karadeniz Teknik Üniversitesi İletişim Fakültesi \\ Halkla İlişkiler ve Reklamcılık Bölümü
}

\section{ÖZET}

Günümüzde akıllı teknolojilerin uygulama alanları giderek artmaktadır. Bu alanlardan biri de AVM'dir. Çünkü bu teknolojiler AVM'lerin müşterileri ile olan iletişimini güçlendirmektedir. Onların beğenilerini, taleplerini, alışkanlıklarını, harcama sıklıklarını vs. öğrenerek müşteri odaklı bir pazarlama stratejisi izlemelerini olanaklı kılmaktadır. Çalışmanın ilk bölümünde "alış veriş merkezleri” ve “akıllı teknolojiler” tanımlanmıştır. Daha sonra “alıveriş merkezlerinde müşteri ilişkileri ve veri-tabanlı pazarlamada akıllı teknoloji kullanımı", "görsellik ve eğlence amaçlı teknoloji kullanımı", "bilgi sağlama ve müşterilere yardım amaçlı teknoloji kullanımı” kategorileri üzerinde durulmuştur ve müşteri ilişkileri açısından akıllı teknolojilerin alışveriş merkezlerindeki uygulama alanları örneklerle ortaya konulmuştur.

Anahtar Kelimeler: Alışveriş Merkezi, Akıllı Teknoloji, Müşteri İlişkileri Yönetimi

\section{ABSTRACT}

Today, application areas of smart technologies is growing fast. One of the these areas is shopping malls. Because these technologies strengthens the communication with customer of shopping malls and learning their; tastes, requirements, habits, frequency of spending etc., make possible to follow a customer-focused marketing strategy.

In the first section, "shopping malls" and "smart technologies" are defined. Then, "at shopping malls use of smart technology in customer relationship and data-based marketing", "The use of technology for visual and entertainment" "the use of technology for providing 
information and assistance to customers" categories are emphasized and rom the standpoint of customer relationship, application areas of smart technologies have been revealed with examples.

Keywords: Shopping Malls, Smart Technologies, Customer Relationship Management

\section{GíRiş}

"Yeni Teknolojilerin kullanımındaki patlamaya bağlı olarak alışveriş merkezleri ve perakende mağazaları gelecekte bu günkünden çok farklı olacak. Birçok perakende analisti gelecekte alışveriş merkezlerinin büyük eğlence merkezleri olacağını, dev kalabalıkları bir araya getireceğini ve alışveriş olanaklarından çok daha fazlasını sunacağını ön görmektedir.” (Lynch, 1992). Yazarın bu satırları yazdığı tarihten bu yana yaklaşık yirmi yıl geçti ve analistlerin ön görüleri neredeyse tamamen gerçekleşti. Bugün hemen hemen tüm sosyo ekonomik gruplar için uygun olanaklara sahip bir AVM bulmak mümkün ve bu AVM'ler alış veriş olanaklarının sunulduğu mekânlar olmaktan çok daha öte bir anlam ifade ediyor. Kimisi yemek yemek için, kimi kıyafet almak için kimi de eğlenceli bir hafta sonu geçirmek için gidiyor AVM'ye ve sonuçta bu merkezler birer sosyal yaşam, paylaşım ve karşılaşma alanı olarak karşımıza çıkıyor.

Her ne kadar alışverişten öte bir anlam ifade etse de bu merkezlerde yapılan her türlü aktivitenin bir maliyeti var ve bu da sonuçta bir alışverişe karşılık geliyor. Ağırlıklı olarak gıda ve gıda dışı perakende sektörü ile eğlence sektöründe hizmet veren firmalar bu merkezler aracılığıyla müşterileriyle buluşuyorlar. $\mathrm{Bu}$ da bu merkezleri temel ihtiyaçların satın alındığ ana merkezler haline getiriyor. Geleneksel alış veriş noktalarının müşteriler tarafindan giderek terkedilmesi ve bu merkezlerin görece daha çok tercih edilmesi AVM'lerin sayısının hızla artmasına neden oluyor. Doğal olarak bu ortam çok ciddi rekabetçi avantajların sunulması gereken bir pazarı doğurmuş oluyor.

Müşterileriyle modern dönemin getirdiği gereklilikleri doğru ouyarak; güvenilir, etkin ve sistematik bir iletişim kurmayı başarabilenler diğerlerine mukayeseyle daha ön plana çıkyor ve pazar paylarını genişletiyor. Burada modern dönemin getirdiği yeniliklerle kastedilen, müşteri odaklı pazarlama yaklaşımı ve buna bağlı olarak müşteri gereksinimlerine cevap verecek her türlü teknolojik donanım, yazılım ve inovasyonu kullanmaktır. İşte tam bu noktada en son teknolojiyle donatılmış bir müşteri ilişkileri yönetimine gerek duyulmaktadır. 


\section{Alışveriş Merkezleri}

Alışveriş merkezleri; merkezi bir birimce dizayn edilen, planlanan, yapılandırılan ve yönetilen perakendeci dükkânların ve çeşitli hizmet kuruluşlarının yer aldığı bir komplekstir. Ticari işletme tiplerini ve farklı hacimlerdeki satış birimlerini içinde barındıran bu kompleksler belli bir alan içindeki tüketicilere hizmet etmek üzere veya belirli bir tüketici grubuna hizmet etmek üzere yapılandırılarak kurulmaktadırlar. Bir başka ifade ile alışveriş merkezleri, tüketicilere rahatlık ve kolaylık sağlamak amacıyla pek çok mağazanın ve dolayısıyla da pek çok ticari malın bir arada bulunduğu perakende satış kompleksidir. $\mathrm{Bu}$ merkezler, tek ve belirli bir plan altında bir araya getirilmiş çeşitli perakendeci mağazaların oluşturduğu bir grup olmasının yanında ayrıca küçük, özellikli mal satan perakendeci mağazalar, sinema, banka, pastane, kafeterya, kuaför, eczane gibi müşterilere rahatlık sağlamak amacıyla pek çok mağazanın bir arada bulunduğu perakende satış komplekslerinden de oluşmaktadır. Bu komplekslerin büyük bir çoğunluğu otopark kolaylığı sağlamaktadırlar.

Son zamanlarda ise birkaç yeni model daha denenmektedir. Örneğin şehirlerden hayli uzakta kurulan "outlet”ler bu modellerden biridir. Buralarda ünlü markaların bir sezon önceki ürünleri indirimli fiyatlarla tüketiciye sunulmaktadır. Bir de bölgesel mall diye adlandırılan çok büyük alışveriş merkezleri oluşturulmaktadır. Amerika'daki "Mall of America" bu konuda iyi bir örnek teşkil etmektedir. Türkiye'de de buna benzer yapılanmalar rağbet görmektedir. Çünkü artık insanlar planlı alışveriş etmektedirler. Bu planlamanın içine hafta sonu alışverişi olarak aile alışverişi girdiğinden, alışveriş olayına çocuk da katılmış durumdadır. Bu yüzden alışveriş merkezlerinde çocukları oyalayabilecek çeşitli aktivitelerin yapılması gerekmiştir. İnsanların hobilerine yönelik mağazalar, tema ağırlıklı mağazalar ve restoranlar oluşmuş, ihtisas mağazaları ortaya çıkmıştır. Böylece alışveriş ile eğlence bir araya gelmiş bulunmaktadırlar. Bu model dünyada olduğu gibi Türkiye'de de büyük bir başarı göstermektedir. (Cengiz, 2002:69)

Alışveriş ve eğlence olgusunu destekleyen etkenler; liberal ekonominin yerleşmesi, yüksek gelir grubunun ve kişi başına düşen gelirlerin artışı, tüketim kültürünün ve yaşam stili odaklı alışverişin (lifestyle retailing) artması gibi olgular, Türkiye genelinde de büyük ölçekli AVM sayısının hızla artmasına neden olmuştur. AVM'ler özellikle 1990'lardan itibaren büyük kentlerimizde önemli yer edinmişler ve Türk halkı tarafindan benimsenerek popüler hale gelmişlerdir. Alışveriş Merkezleri ve Perakendecilik Derneği'nin istatistiklerine göre 
1980'lerin sonunda Türkiye'de yalnızca 3 adet AVM var iken, bu rakam 1990'lar sonunda 31, 2000 yılı sonunda 69'a ulaşmıştır. 2005 yılına geldiğimizde ise sayısı 103'e ulaşan AVM'ler (Saygın,2006:97) 2010 yılı Mayıs sonu itibariyle 242 adet olarak belirlenmiştir. (http://www.ampd.org).

\section{Akıllı Teknoloji}

Akıllı teknoloji ürünleri, ileri teknolojileri en üst düzeyde bir araya getirmektedir. $\mathrm{Bu}$ teknolojilerin akıllı olma özellikleri acaba bu ürünler kendi durumlarının farkındalığını yaşıyorlar mı ve gerçekten reaksiyon yeteneğine sahipler mi? Sorularını akla getirmektedir. İşte bu soruların içeriğindeki farkındalık ve reaksiyon yeteneği özellikleri, bir teknolojinin "akıllı teknoloji” olarak kabul edilebilmesi için ortaya koyması gereken anahtar vasıflara karşılık gelmektedir. Burada farkındalıkla kastedilen teknolojinin çevresi, koşulları ya da kendi hareketleri ile ilgilidir. Reaksiyonlar ise harici etkilere karşı kendini koruyabilmesi, tamir edebilmesi ve fonksiyonlarını içinde bulunduğu spesifik duruma adapte edebilmesidir.

Karşılaşılan yeni durumlara yönelik olarak fonksiyonlarını geliştirmek üzere mevcut durumdaki değişiklikleri algılayabilen ve ölçebilen teknolojiler, performans, etkinlik, maliyetlerin yönetilmesi ve dayanıklılık gibi alanlarda çok önemli avantajlar sunmaktadır.

Akıllı teknoloji uygulamalarındaki genişlik ve derinlik, tıp, mühendislik ve pazarlama gibi alanlarda avantajlar elde edilmesini sağlamaktadır. Her uygulama kendi alanına uygun özgün tasarım kriterleri gerektirmektedir ancak her yeni üretilen akıllı teknoloji temelde aynı soruna çözüm üretmek için geliştirilmektedir. Bu sorun, cihazların nasıl bir sistem içinde minimum maliyet ve karışıklıkla uyumlu bir biçimde entegre edileceğidir. Bu durum da doğası gereği, disiplinler arası bir yaklaşıma ve çok sayıda farklı teknolojik bilgiye dayalı bir tasarım felsefesini gerektirmektedir. (Worden, Bullough, Haywood,2003:1-2) 


\section{Alıveriş Merkezlerinde Müşteri İlişskileri ve Veri-Tabanlı Pazarlamada Akıllı Teknoloji Kullanımı}

Müşteri ve müşteri sadakati günümüzün rekabetçi dünyasında giderek artan bir öneme sahiptir. İşletmeler pazar payı yerine müşteri payı anlayışını izlemektedirler ve müşteriye ait özel veritabanları oluşturmaktadırlar. Oluşturulan bu veri tabanları aracıllığıyla sürdürülen pazarlama stratejsine de müşteri ilişkileri yönetimi denmektedir.

Müşteri veri tabanları; bireysel müşteriler ya da olasılıklarla alâkalı olan, organize edilmiş, kapsamlı, içinde coğrafik, demografik, psikolojik ve davranışsal bilgilerin bulunduğu verilerdir. Veri tabanlı pazarlama ise, müşteri veri tabanlarının ya da diğer veri tabanlarının kullanılmasına dayanan pazarlama anlayışıdır. (Kotler, Armstrong, 1999: 508)

Veri tabanı pazarlaması Pickton, Broderick (2001:50) tarafindan da şu şekilde tanımlanmaktadır. Mevcut ve muhtemel müşteri bilgisi, rakip işletmelerin bilgisi ve fïma içi bilgiye dayanan müşteri ilişkileri yönetimine interaktif bir yaklaşımdır. Veritabanı; doğrudan pazarlama, bilgisayar yardımlı satış desteği için bilgi sağlamak, müşteri bilgisini ve hizmet sistemlerini desteklemek için kullanılmaktadır.

Veri tabanlı pazarlama aynı zamanda, bilgisayar ve multi medya teknolojilerinin de yaygın olarak kullanıldığg alanlardan biridir. Bu alandaki mevcut teknolojiler Alışveriş merkezlerine ve onların kiracılarına müşteri davranışlarını daha iyi anlayabilme ve ön görebilme olanağı sunmaktadır. Bu alanda ABD'de ortaya konulan örnek bir uygulamayı Rouland (1994:32) şu şekilde aktarmaktadır: "Valley View Center (LaSalle Partners tarafindan kurulan) Dallas'ta yüksek teknolojiye dayalı bir müşteri sadakati programı olan akıllı müşteri klübünü kurmak için bilgisayar temelli kiosklar uygulamasını gerçekleştirdi. $\mathrm{Bu}$ program aracılığıyla müşteriler hem bir takım bilgi ve olanaklara sahip oluyor hem de kendileri hakkında bir takım demografik ve psikografik bilgileri sunmuş oluyorlar. Program şu şekilde çalışıyor: Müşteriler alşverişveriş merkezini her ziyaret ettiklerinde bilgisayarlı kiosklara giriş yapabilecekeleri (ATM cihazlarındakine benzer biçimde) bir PIN numarası belirliyorlar. $\mathrm{Bu}$ numaralarla kisosklara giriş yapan müşteriler ödüller kazanma hakkına ve indirimlerden yararlanma olanağına sahip oluyorlar. Ayrıca bu bilgisayarlar müşterilere alışveriş merkezindeki aktiviteler, özel satışlar ve hatta çekiliş kuponları hakkında bile bilgi veriyor." 
Bu teknolojiler mhtemlen giderek daha fazla sayıda alışveriş merkezinde ve perakende mağazacılık alanında, müşterilerin harcama profillerini, ortalama ne kadar harcama yaptıklarını, ne tür yemek alanlarını tercih ettiklerini, hangi spesifik ürün, mağaza ve markaların sadık müşterileri olduklarını takip etmek amacıyla kullanılacaktır. (clodfelter,1996:61)

Teknolojik alt yapıya dayalı olarak yapılan bu izleme çalışmaları sonucu elde edilen bilgiler CRM (Customer Relatioship Management) kapsamında müşteri sadakatini kazanmaya yönelik olarak kullanılmaktadır. Müşterinin dilediği ürün ve hizmetlerin reklam, tanıtım ve doğrudan pazarlaması veri tabanları sayesinde daha etkin ve verimli bir biçimde yapılabilmektedir.

\section{Eğlence ve Ticari Amaçlı Görsel Teknoloji Kullanımı}

Teknolojiyi kullanarak müşterileri eğlendirmek alışveriş merkezlerinin ve perakendecilerin kendilerini faklılaştırma için kullandıkları yöntemlerden biridir. Aslında Eğlencenin ve görselliğin alışveriş merkezlerinde ticari amaçlı kullanımı yeni bir olgu değildir. Başlangıçtan itibaren bunlar farklı satış teknikleri olarak kullanılagelmiştir. Çocuklar için oyun alanları, yemek için ayrılan bölümler, moda gösterileri, sergiler ve gösteriler neredeyse tüm alışveriş merkezlerince kullanılmıştır. Ancak müşterileri çekmek ve eğlendirmek için teknolojiden bugünkü kadar geniş ölçüde yararlanılmamıştır. (clodfelter,1996:61-62)

Günümüzde alışveriş merkezlerinde teknolojik alt yapının kullanıldığı görsel etkinlikler ve eğlence aktiviteleri uygulanmaktadır. Ülkemizde de görsel teknolojinin ticari olarak en yaygın kullanım alanı sinemalardır ve alışveriş merkezlerinin genelinde sinema mevcuttur. Sinemanın yanı sıra İstanbul Capacity’de örneği görülen ve havuz fıskıyeleri ile senkronize edilen ses ve 1şık gösterileri teknolojinin eğlence amaçlı kullanımına örnek teşkil etmektedir. Bunun yanısıra 5 boyutlu deneyim sağlayan yapay görsel gerçeklik hareketli sinema odaları İstanbul Capacity'de çocukların hizmetine sunulmuştur. Ayrıca teknolojik oyun parkları Carousel, Flyinn gibi pek çok alışveriş merkezinde bulunmaktadır. 
Yine İstanbulda bulunan Torium Alışveriş Merkezi içerisindeki Türkiye'nin ilk kar eğlence merkezi 'Torium Snowpark' da alışveriş merkezlerinde teknolojinin eğlence amaçlı kullanımına bir örnektir. Dört mevsim kış sporları ve kar eğlencesi yaşatmak üzere tasarlanan eğlence merkezinde yapay olarak üretilen karın kalitesi ise Uludağ ve Kartalkaya gibi yüksek rakımlı yerlere yağan karın kalitesine eş değerdir. İçerisinde kızaklı tüp kaydırak, 55 metre uzunluğunda 3 sıçrama rampalı snowboard parkuru, çift ahşap kızak rampası, halatlı dăg tırmanışı, kayak eğitim parkuru ve kar oyun alanı bulunan snowpark' ’n kayak ve snowboard eğitimleri vermeye uygun pistleri de bulunmaktadır. (http://www.sondakika.com)

Teknolojik alt yapıya dayalı görselliğin ticari kullanımına ise şöyle bir örnek vermek mümkündür. Türkiye'de teknoloji ürünleri perakendeciliği yapan Bimeks, Bluetooth'lu reklam panosu Bitotem'u (mesajları mobil telefonlara gönderen araç) mağaza içine yerleştirerek Bimeks tanıtım videosu ve günün indirimli ürününü öğrenebileceği bir reklam mesajını Bluetooth aracılığıyla kullanıcılara iletilmiştir. Aynı şekilde Metroport Alışveriş Merkezi, Bluetooth noktalarından "I love Metroport" logolu içerikleri indiren ziyaretçilerden her 50. kişiye ücretsiz sinema bileti hediyesi vererek, ziyaretçilerle alışveriş merkezi arasında duygusal bağ kurması yanında Bluetooth aracılığıyla reklam kampanyalarına hazırlık yapmıştır. (www.bluetoothserver.com).

\section{Teknolojinin Bilgi Sağlama ve Müşterilere Yardım Amaçlı Kullanımı}

$\mathrm{Bu}$ konuda ilk akla gelen uygulamalardan biri alış veriş merkezi içindeki elektronik yönlendirme panolarıdır. Pek çok avm daha standart modelleri ekonomik açıan tercih etse de akıllı teknolojinin başlıca faydalı ürünleri arasında yer alan bu tip dijital panolar bulunduğunuz yerden sizi gitmeniz gereken yere yönlendirmede odukça başarılıdır.

$\mathrm{Bu}$ başlık altında değerlendirilebilecek bir başka örnek de henüz seri üretimine geçilmemiş olan fakat bu alanda önemli sayılabilecek bir inovasyondur. RNK Teknoloji Elektronik Yazılım Ltd. Şti. tarafından geliştirilen yazılım bilinçli müşteriler ile, Maksimum hizmet sunarak rekabet avantajı elde etmek isteyen AVM yönetimleri arasında köprü kuracak şekilde tasarlanmıştır. 
Müşteriye zamandan tasarruf sağlayacak şekilde tasarlanan bu yazılım, ürün aramada yardımcı olmak, sepet toplamını göstermek (harcanan para), hızlı kasa uygulamaları ile kasada daha az beklemeyi sağlamak gibi avantajlar sunmaktadır. Tüm bu hizmetleri gerçekleştirirken Alışveriş Merkezlerine de bir takım kazanımlar sağlamaktadır. Örneğin, sepet toplamı $80 \mathrm{TL}$ olan müşterisine $100 \mathrm{TL}$ barajlı kampanyasından faydalanması için yardımcı olmaktadır. Mağaza içinde yeni teşhir ettiği bir ürünü veya müşterilerine sunmayı çok istediği bir ürünü günlük hatta saatlik olarak tüm müşterilere sunabilmektedir. Kasadaki operasyonlardan daha rahat sonuçlar toplayarak mağaza yönetimine göre özelleştirecek olan yazılım, altyapısıyla birçok farklı uygulamalar da geliştirilebilecek şekilde tasarlanmıştır.

Bu yazılımın yüklü olduğu cihaz, Mobil olarak çalışan Elektronik bir sistemdir. İlk etapta Sepetli alışverişlerde Müşteri kartı olan mağazalarda kullanılabilecektir. Gün içerisinde 8-10 saat çalışabilmekte, gün sonunda şarj ünitesinde şarj olmaktadır. Cihaz, AVM yönetimi bilgisayar sitemiyle kablosuz olarak haberleşmekte ve tüm verileri buradan almaktadır. Manyetik Kart Okuyucu (Müşteri Kartları ile müşteri tanımak İçin) ve Barkot okuyucuya sahiptir. Müşteri kartını okutunca ona özel olarak çalışmakta ve asistanlığa başlamaktadır. Müşteri, mağaza içinde istediği bir ürünün barkodunu cihaza okutarak ürün bilgilerini görebilmekte ve cihazın dokunmatik ekranı aracılığıyla interaktif bir alışveriş deneyimi yaşamaktadır. (http://www.rnkteknoloji.com/Medya/star.htm)

\section{Sonuç}

Günümüzde müşterilerin bir AVM'den merkezinden beklentileri giderek artmakta ve çeşitlenmektedir. Zaman kazandırma, maliyet düşüklüğü, prestij sağlaması, eğlence olanaklarına sahip olması, karmaşık olmaması vs. şeklinde sıralanabilecek olan bu beklentilere AVM'ler tarafından iyi yanıt verilebilmesi için ise akıllı teknolojilerin kullanıldığı müşteri ilişkileri yönetimi adeta bir zorunluluktur. Çünkü çalışmada da belirtildiği gibi AVM'lerin sayısı hızla artmaktadır ve bu beklentileri standart düzeylerde karşılamak artık yeterli olmamaktadır. Gerek maliyetlerin yönetilebilmesi, gerek kârlılığın ve verimliğin artırabilmesi, gerekse pazar payının korunması ya da genişletilmesi açısından akıllı teknolojiye dayalı müşteri odaklı pazarlama felsefesi son derece önemlidir. AVM binasının henüz tasarım-yapım aşamasında gerekli altyapıyı hazırlamak ve sonrasında tüm inovasyonlara açık olmak ise bu felsefenin temelini oluşturmaktadır. 


\section{KAYNAKÇA}

Cengiz, E. Özden B. (2003), "Perakendecilikte Büyük Alışveriş Merkezleri ve Tüketicilerin Büyük Alış Veriş Merkezleri İle İlgili Tutumlarını Tespit Etmeye Yönelik Bir Araştırma, Ege Akademik Bakış, Ege Üniversitesi İktisadi İdari Siyasi Bilimler Dergisi, 2 (1):64-79.

Clodfelter, R., \& Overstreet, J. (1996), Technological Profile of Shopping Centers: Present and Future, The Journal of Shopping Center Research, (Spring/Summer).

Helvacıoğlu B. (2000). "Globalization in the neighborhood: from the nation-state to Bilkent Center" International Sociology.Vol 15 (2). pp. 326 -3 42.

Kotler P., Armstrong G. (1999), Principles of Marketing, Eight Ed, Prentice Hall, International Inc, New Jersey.

Lynch, A. (1992),"Training for a New Ball Game: Retailing in the 21st Century" The Futurist, (July-August) p.36-40.

Pickton D., Broderıck A., (2001), Integrated Marketing Communications, Pearson Education, Barcelona, Spain.

Rouland R. (1994), “The Reality is the Dream: Creative Retail Systems”, DM, (April)

Saygın, N. (2006). Alışveriş Merkezleri: Türk Kentlerindeki Yeni Tüketim Cennetleri, Planlama Dergisi - İmir Sayısı, Sayı: 2006/3. s.s. 97-103.

Worden, K., Bullough, W.A., Haywood, j.(2003). Smart Technologies. Singapore: World Scientific Publishing,

\section{INTERNET}

AMPD Perakende Endeksi Kasim 2010.

http://www.ampd.org/arastirmalar/default.aspx?SectionId=164 adresinden 03.01.2011 tarihinde edinilmiştir.

Bluetooth'la Pazarlama Nedir?. http://www.bluetoothserver.com/tag/bluetooth-ile-pazarlama adresinden 03.01.2011 tarihinde edinilmiştir.

Akıllı Alışveriş Asistanı. http://www.rnkteknoloji.com/Medya/star.htm adresinden 06.01.2011 tarihinde edinilmiştir.

Türkiye'nin En Eğlenceli Avm'si Torium Açıldl. http://www.sondakika.com/haber-turkiye-ninen-eglenceli-avm-si-torium-acildi-2344947/ adresinden 09.01.2011 tarihinde edinilmiştir. 